Mr. R. M. Laing has contributed a brief article to To-morrow, a New Zealand independent fortnightly (Nov. 10, 1937).

The Nelsonian, the magazine of Rutherford's school, Nelson College, has collected notices and published a photograph of the old Rutherford home since demolished. One of the Houses at Nelson College is now known as Rutherford House.
Dr. C. M. Focker is also preparing a full bibliography of the publications of Lord Rutherford to be given in the Transactions of the Royal Society of New Zealand. The list is still incomplete, but the present number of books, letters and articles has already reached a total of some two hundred and sixty. It will be a valuable index of Lord Rutherford's activities.

\title{
The Assessment of Nutrition
}

$\mathrm{I}^{\mathrm{T}}$ is not often that a single problem is, at one time, and without deliberate co-ordination, studied by medical men, scientific workers and sociologists. This is the case with the 'assessment of nutrition'. Everyone who is interested should read a contribution* which both shows how urgent the problem is and (by implication, since the author tactfully understates his case) indicates possible modes of solution. Everyone should also read the discussion which follows the paper.

Mr. Huws Jones defines the problem : To discover undernourished children that they may be fed. There is reason to believe the methods in use are not discovering them all. Three possible improvements are suggested; more frequent detailed medical examination, frequent rapid survey to select cases for detailed examination, or the use of a physical yardstick to select cases for detailed examination. Since questions of finance exclude the first suggestion (yearly examination of all children would mean trebling the number of school medical officers), and the second is not considered likely to be useful, attention is concentrated on the third.

The object of the inquiry was to show whether any system of physical measurements can be used to avoid unnecessary extension of medical examination, to select probable cases for the decision of the medical officer. School children were therefore medically examined and carefully measured. Children from the same school were examined by the same doctor on two occasions ; the same children were examined by different doctors; the doctors "were urged to take as much time as they wanted over the assessment of each boy". Finally, the grading of the children by physical measurement and by medical opinion was compared.

The comparison showed that the percentage of children graded by medical examination as subnormal increased steadily from good to poor schools ; that height and weight, at each age, improved with social class ; that of children graded medically in the same nutrition class those in better schools were taller and heavier than those in poorer schools, and that height and weight in all classes of school im. proved with nutrition elass. Nutrition grades, as determined by medical examination, "are distinguished best by weight, then by chest, and finally by height". But no combination of measurements could be found which could be used to pick out exactly the same children as the medical officers would select as a result of their examination.

The discussion is illuminating. Dr. Magee ignored

* Jones, R. H., "Physical Indices and Clinical Assessments of the Nutrition of Schoolchildren" (with Discussion), J. Roy. Statist. Soc., 101, 1-52 (1938). the economic reason for seeking a time-saving substitute for clinical examination and wished to combine anthropometric with clinical examination and even add on physiological tests. Dr. Glover, of the Board of Education, cheerfully delivered himself into the hands of his critic on two counts, first that the discrepancies between the assessments of the different medical men could be explained as due to borderline cases, and second that the judgment of "teachers, school nurses, school attendance officers and others in regular contact with the children... could go far towards filling any gaps left by clinical assessment".

From the former of these suggestions, Mr. Huws Jones deduced that, in some areas, more than half the children examined were on the borderline between satisfactory and unsatisfactory nutrition, which makes the published reports of the Board seem "Too rosy". In view of the second, he wondered what need there is to employ medical men at all for this purpose if teachers appear to be so successful in picking out children who escape the doctors' scrutiny.

Dr. Daley suggested that the important thing was, not the anthropometric measurements at a given moment, but periodic measurements to show rate of growth.

Apart from the general conclusion that physical measurements give an index "at least as satisfactory as a careful and complete clinical examination", the issue is left in doubt. Indeed, Mr. Jones himself questions whether the best index he found (Tux. ford's) can be regarded "as a satisfactory measure of nutrition". But, if the problem be accepted as originally enunciated, namely, to discover under. nourished (that is, underfed) children in want of more food, then, on analogy with animal husbandry, physical measurements are the simplest and only reliable criteria. If, on the other hand, as appears from several parts of the discussion, something more difficult and subtle must be read into the problem, which becomes a complicated mixture of questions of disease and malnutrition, as well as underfeeding, then the role of the doctor appears to be to select from amongst those shown by physical measurement to be below an accepted standard: $(a)$ those whose condition is referable to any detectable disease con. dition not nutritional in origin; and $(b)$ those suffering not from gross lack of food, but from some particular deficiency. The first would receive ap. propriate treatment and all the others would be fed; unless, of course, as $\mathrm{Mr}$. Jones rationally suggestsand his study has given a general indication in favour of this solution-all the children from poor families are fed. 